\title{
Watermelon rind-mediated green synthesis of noble palladium nanoparticles: catalytic application
}

\author{
R. Lakshmipathy $\cdot$ B. Palakshi Reddy $\cdot$ \\ N. C. Sarada $\cdot$ K. Chidambaram $\cdot$ Sk. Khadeer Pasha
}

Received: 19 January 2014/ Accepted: 27 March 2014/Published online: 19 April 2014

(C) The Author(s) 2014. This article is published with open access at Springerlink.com

\begin{abstract}
The present study reports the feasibility of synthesis of palladium nanoparticles (Pd NPs) by watermelon rind. The aqueous extract prepared from watermelon rind, an agro waste, was evaluated as capping and reducing agent for biosynthesis of palladium nanoparticles. The formation of Pd NPs was visually monitored with change in color from pale yellow to dark brown and later monitored with UV-Vis spectroscopy. The synthesized Pd NPs were further characterized by XRD, FTIR, DLS, AFM and TEM techniques. The synthesized Pd NPs were employed in Suzuki coupling reaction as catalyst. The results reveal that watermelon rind, an agro waste, is capable of synthesizing spherical-shaped Pd NPs with catalytic activity.
\end{abstract}

Keywords Watermelon rind · Pd nanoparticles · Green synthesis · Catalysis · Particle size

\section{Introduction}

Biosynthesis of nanoparticles is receiving increased attention due to the advancements in chemical and

R. Lakshmipathy $\cdot$ N. C. Sarada

Environmental and Analytical Chemistry Division, School of Advanced Sciences, VIT University, Vellore 632014,

Tamilnadu, India

B. Palakshi Reddy

Department of GEBH, Sree Vidyanikethan Engineering College,

Tirupati, AndhraPradesh, India

K. Chidambaram $\cdot$ Sk. Khadeer Pasha $(\bowtie)$

Centre for Excellence in Nanomaterials, School of Advanced

Sciences, VIT University, Vellore 632014, Tamilnadu, India

e-mail: khadheerau@yahoo.com; khadheerbasha@lycos.com physical methods. Green synthesis of nanoparticles is cost effective and environmentally friendly as it has unique properties and enormous applications in biological tagging, pharmaceutical and optoelectronics (Jacob et al. 2012). Palladium nanoparticles (Pd NPs) are of interest because of their catalytic properties and unique application in sensors and catalysis (Bankar et al. 2010). Palladium nanoparticles are conventionally synthesized by chemical, electrochemical or sonochemical methods, but in recent years many researchers have reported green and eco-friendly way of synthesis of palladium nanoparticles using plant extracts, microbes and agricultural wastes (Sathishkumar et al. 2009; Saxena et al. 2012; Narayanan and Sakthivel 2011). Recently, agricultural wastes such as banana peel (Bankar et al. 2010), and custard apple peel (Roopan et al. 2011) which are rich in polyphenols, lignin and pectin were explored in the synthesis of palladium nanoparticles. The potential of other fruit peel extracts as surfactants/reductants for synthesis of Pd NPs needs to be fully explored.

Watermelon (Citrullus lanatus) being the largest and heaviest fruit, is one of the most abundant and cheapest available fruits in India with 3 lakh tones produced every year. Red flesh of watermelon present inside is sweet, edible and used for juices and salads but the outer rind is considered as waste and has no commercial value. Watermelon rind (WR) consists of pectin, citrulline, cellulose, proteins and carotenoids (Rimando and Perkins-Veazie 2005; Andrew et al. 2008; Quek et al. 2007) which are rich in functional groups such as hydroxyl (cellulose) and carboxylic (pectin). In this paper, for the first time, watermelon rind powder extract (WRPE) was used as capping or reducing agent for synthesis of Pd NPs. 


\section{Materials and methods}

Preparation of the extract

Watermelon rinds (WR) were obtained from local fruit market and washed with tap water followed by double distilled water. After thorough washing, WR was cut into small pieces and dried under sun light for 7 days. The dried WR pieces were washed repeatedly with hot water $\left(70^{\circ} \mathrm{C}\right)$ to remove any soluble matter present and then dried in an oven at $85{ }^{\circ} \mathrm{C}$ for $48 \mathrm{~h}$. The oven-dried WR was powdered using a conventional grinder and sieved through 100 mesh sieve standard. To $50 \mathrm{~mL}$ of distilled water, $1 \mathrm{~g}$ of sieved WR was added and boiled in a water bath for $30 \mathrm{~min}$ to prepare aqueous extract. The extract was cooled to room temperature and filtered through $0.45 \mu \mathrm{m}$ filters and freshly prepared extract was used for synthesis. The aqueous extract was termed as watermelon rind aqueous extract (WRAE).

Biosynthesis of palladium nanoparticles

The source of palladium was palladium chloride in distilled water. For synthesis of Pd NPs, $20 \mathrm{~mL}$ of $1 \mathrm{mM} \mathrm{PdCl}_{2}$ solution was added with $10 \mathrm{~mL}$ of WRAE and incubated in a temperature controlled shaker at $150 \mathrm{rpm}$ for $24 \mathrm{~h}$ at $30{ }^{\circ} \mathrm{C}$. Parameters such as reactant ratio, $\mathrm{pH}$ and reaction time were optimized. The formation of Pd NPs was visually confirmed and later by UV-Vis spectrophotometer. At optimized conditions, the obtained colloidal solution was centrifuged at $10,000 \mathrm{rpm}$ for $10 \mathrm{~min}$ and the solid was washed with water, methanol and acetone to remove biomolecules. The solid was dried at $85{ }^{\circ} \mathrm{C}$ and used for further characterization.

\section{Characterization of palladium nanoparticles}

The nanoparticles synthesized on reduction by WRPE were initially characterized using UV-Vis spectrometer (Hitachi, Model: U-2800) from 200 to $600 \mathrm{~nm}$. Further characterization was done using FTIR (Thermo Nicolet, Avatar 330, USA) for identification of functional groups present in WRAE and Pd NPs between 4,000 and $400 \mathrm{~cm}^{-1}$, crystalline nature of synthesized Pd NPs was recorded with XRD (Bruker Germany, D8 Advance diffractometer), surface morphology and surface roughness were examined with AFM (Nanosurf 2 Easyscan), TEM (Tecnai 10, Philips) and dynamic light spectroscopy (Delsa Nano $\mathrm{S}$, Backman Coulter, USA) was equipped to know the size and shape of the as-synthesized Pd NPs.

Application in catalysis

The as-synthesized Pd NPs were employed as catalyst for Suzuki coupling. To a solution of Pd NPs (2 mol\%, $0.01 \mathrm{~g}$ in water $10 \mathrm{~mL}$ ), $\mathrm{K}_{2} \mathrm{CO}_{3}$ ( $2 \mathrm{mmol}, 0.27 \mathrm{~g}$ ) was added followed by iodobenzene $(1 \mathrm{mmol}, 0.11 \mathrm{~g})$ and phenylboronic acid $(1.5 \mathrm{mmol}, 0.18 \mathrm{~g})$. The reaction was stirred at room temperature until completion of the reaction. The progress of the reaction was monitored through TLC. After completion of the reaction, the reaction mixture was centrifuged and filtered. The filtrate was evaporated and the crude product was purified by column chromatography (petroleum ether).

\section{Results and discussion}

Polyhydroxylated molecules present interesting dynamic supramolecular associations facilitated by inter- and intramolecular hydrogen bonding resulting in molecular level capsules, which can act as templates for nanoparticles growth (Hebeish et al. 2010). Recently, watermelon rind was reported to bind cations and cationic dyes from aqueous solution (Lakshmipathy et al. 2013; Lakshmipathy and Sarada 2013a, b). Similarly, the negatively charged groups of extract facilitate the attraction of positively charged palladium cations towards the polymeric chain followed by reduction with the existing reducing groups. The mechanism predicted was to be a two-step process, i.e., atom formation and compounding of the atoms. In the first step, a portion of palladium ions in the solution is reduced by the available reducing groups of WRAE. The atoms thus produced act as nucleation centers and catalyze the reduction of remaining palladium ions present in the bulk solution.

\section{Optimization of reaction conditions}

Preliminary experiments were carried to standardize the reaction conditions. The reactant ratio, $\mathrm{pH}$ and contact time were monitored for the standardization of Pd NPs synthesis. Initially, the reaction time was optimized for synthesis of Pd NPs based on the absorbance. It was observed that with the increase in time, the number of Pd NPs was found to increase and attained saturation at $24 \mathrm{~h}$. Further experiments were carried out at $24 \mathrm{~h}$ of contact time. The effect of $\mathrm{pH}$ on formation of $\mathrm{Pd}$ NPs was monitored at $\mathrm{pH} 2,4,6$ and 8 and found that $\mathrm{pH} 6$ showed the rapid formation of Pd NPs. The Pd source to extract ratio was varied from 1:0.2 to $1: 2$ and it was observed that $1: 0.5$ ratio of $\mathrm{PdCl}_{2}$ to WRAE was found to yield maximum amount of Pd NPs beyond that found to be constant. Hence, bulk synthesis of Pd NPs was carried out at $\mathrm{pH} \mathrm{6,} \mathrm{1:0.5} \mathrm{reactant} \mathrm{ratio} \mathrm{for}$ $24 \mathrm{~h}$ of reaction time.

\section{Characterization of Pd NPs}

The formation of $\mathrm{Pd}$ NPs was visually monitored by change in color of solution from pale yellow to dark brown. 


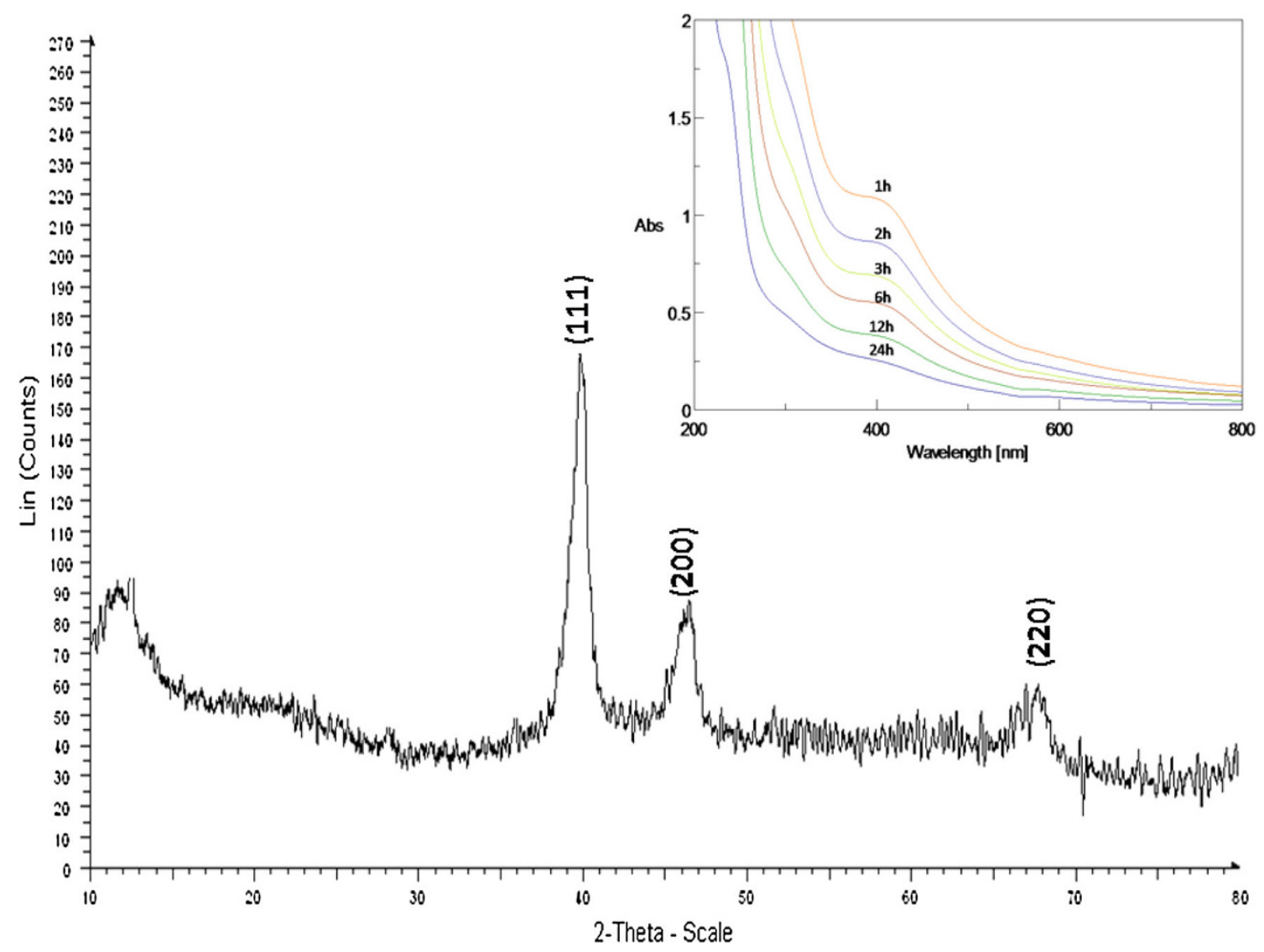

Fig. 1 XRD patterns of synthesized Pd NPs mediated by WRAE (inset UV-Vis spectra of reaction mixture with respect to time)

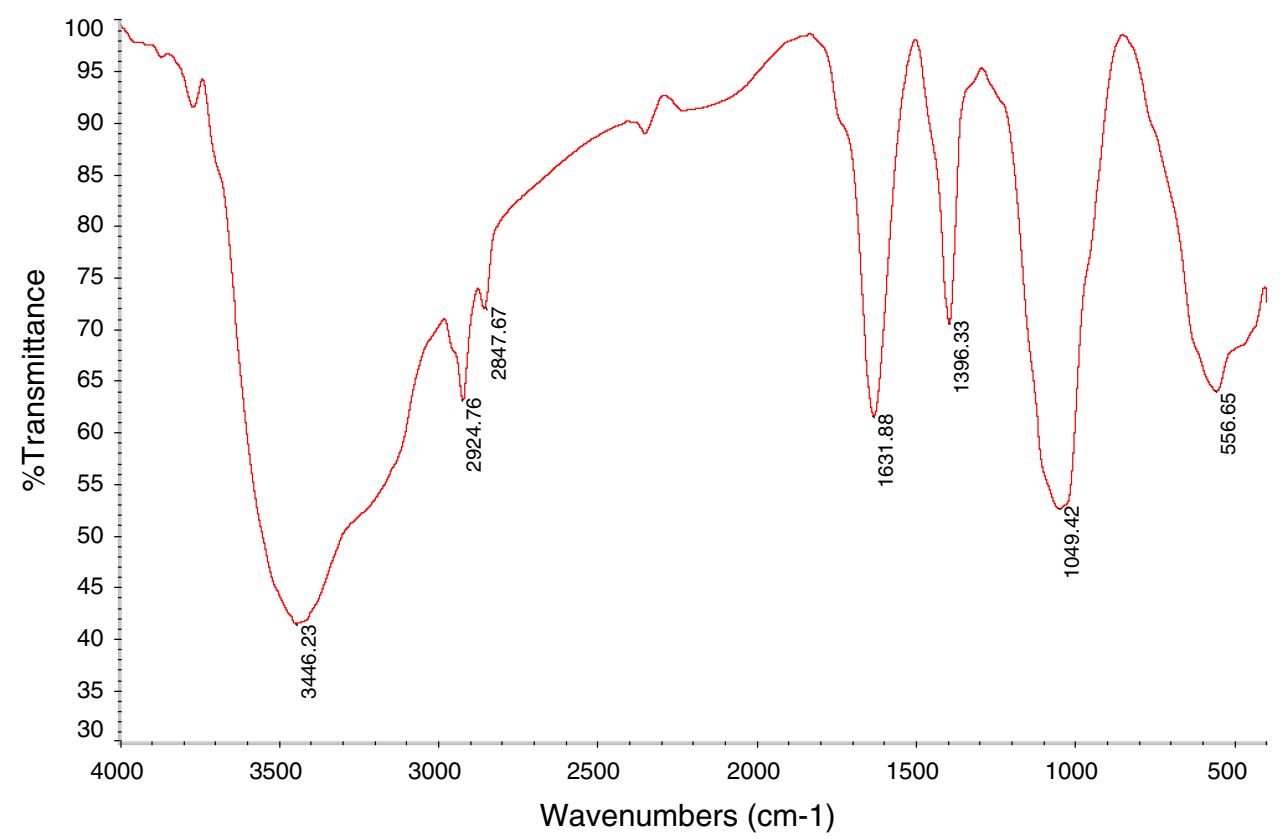

Fig. 2 FTIR spectra of Pd NPs mediated by WRAE 

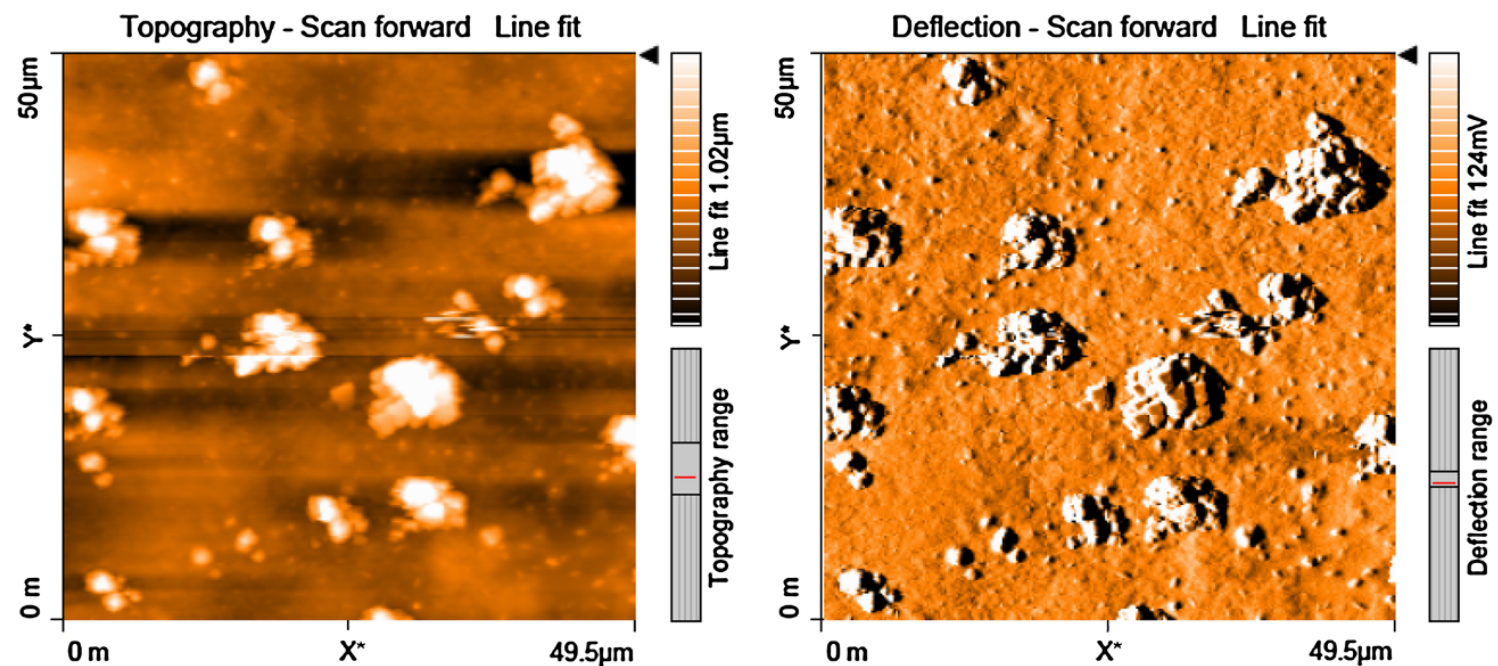

Fig. 3 AFM images of Pd NPs mediated by WRAE
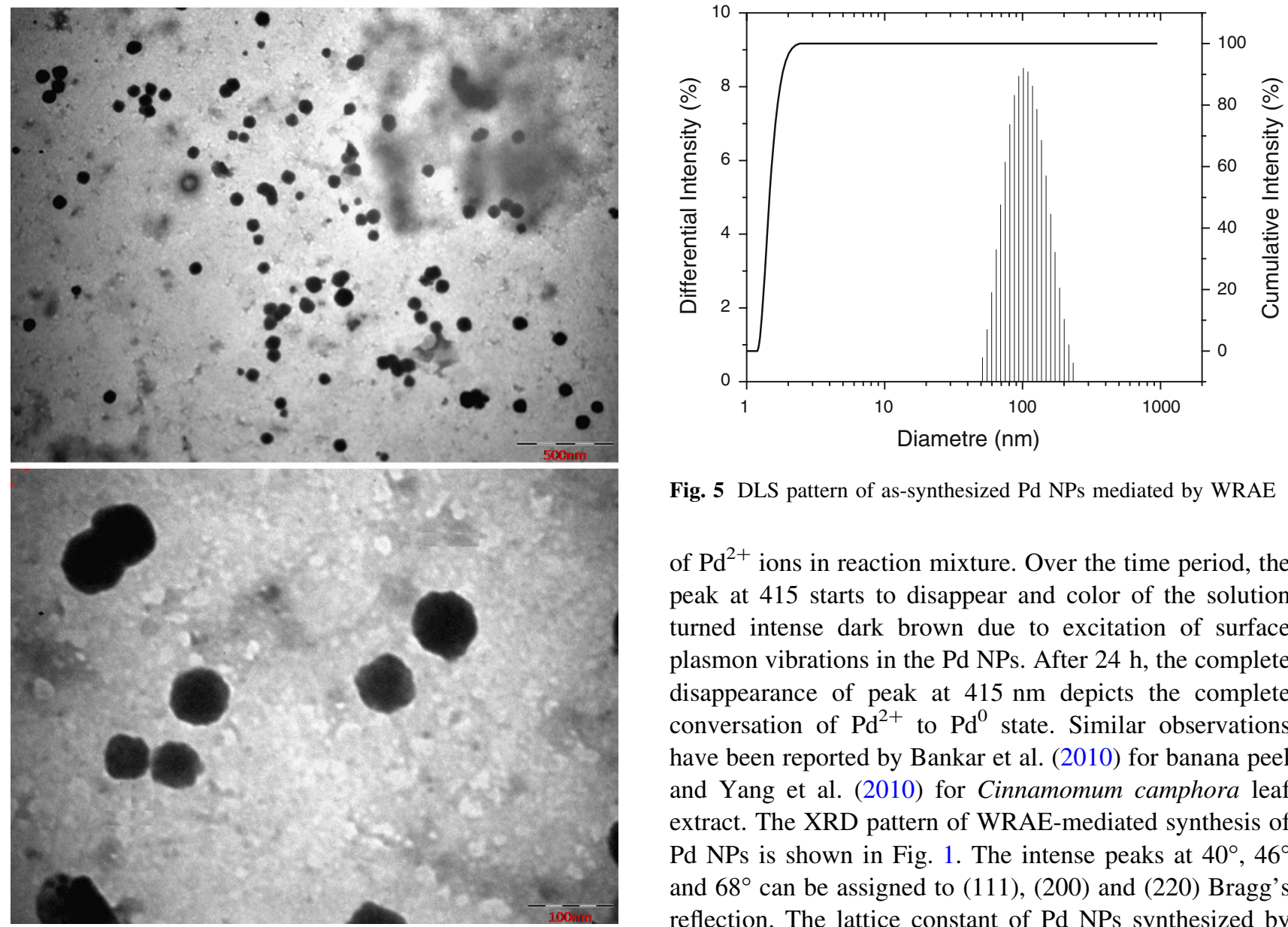

Fig. 5 DLS pattern of as-synthesized Pd NPs mediated by WRAE

of $\mathrm{Pd}^{2+}$ ions in reaction mixture. Over the time period, the peak at 415 starts to disappear and color of the solution turned intense dark brown due to excitation of surface plasmon vibrations in the Pd NPs. After $24 \mathrm{~h}$, the complete disappearance of peak at $415 \mathrm{~nm}$ depicts the complete conversation of $\mathrm{Pd}^{2+}$ to $\mathrm{Pd}^{0}$ state. Similar observations have been reported by Bankar et al. (2010) for banana peel and Yang et al. (2010) for Cinnamomum camphora leaf extract. The XRD pattern of WRAE-mediated synthesis of Pd NPs is shown in Fig. 1. The intense peaks at $40^{\circ}, 46^{\circ}$ and $68^{\circ}$ can be assigned to (111), (200) and (220) Bragg's reflection. The lattice constant of Pd NPs synthesized by WRAE was in agreement with joint committee of powder diffraction standards (JCPDS).

To identify the capping/reducing agents present and

Figure 1 (inset) shows the UV-Vis spectra of reaction mixture $\left(\mathrm{PdCl}_{2}\right.$ solution and WRAE) with respect to time. The observed peaks at $415 \mathrm{~nm}$ at $1 \mathrm{~h}$ indicate the presence predict their role in the synthesis of Pd NPs, FTIR measurement was done. The FTIR spectrum of Pd NPs shows peaks at various wavenumbers corresponding to different 
Fig. 6 Scheme representing the Suzuki coupling reaction mediated by Pd NPs synthesized by WRAE

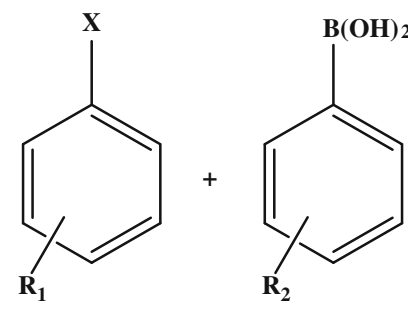

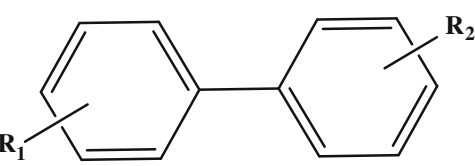

Table 1 Pd NPs catalyzed Suzuki coupling reaction with aryl halide and phenylboronic acid

\begin{tabular}{lllllll}
\hline Entry & $\mathrm{X}$ & $\mathrm{R} 1$ & $\mathrm{R} 2$ & \multicolumn{2}{l}{ Reac. time (h) } & \% Yield \\
\hline 1 & $\mathrm{I}$ & $\mathrm{H}$ & $\mathrm{H}$ & 2 & 98 & $66-67$ \\
2 & $\mathrm{I}$ & $4-\mathrm{NO}_{2}$ & $\mathrm{H}$ & 2 & 93 & $113-115$ \\
3 & $\mathrm{Br}$ & $\mathrm{H}$ & $\mathrm{H}$ & 3 & 96 & $66-67$ \\
4 & $\mathrm{Br}$ & $3-\mathrm{NO}_{2}$ & $\mathrm{H}$ & 2.5 & 94 & 58 \\
5 & $\mathrm{Br}$ & $4-\mathrm{NO}_{2}$ & $\mathrm{H}$ & 2 & 95 & $114-115$ \\
6 & $\mathrm{Br}$ & $4-\mathrm{CH}_{3}$ & $\mathrm{H}$ & 3 & 92 & $42-44$ \\
7 & $\mathrm{Br}$ & $3-\mathrm{OCH}_{3}$ & $\mathrm{H}$ & 3.5 & 90 & liq \\
8 & $\mathrm{Br}$ & $4-\mathrm{OCH}_{3}$ & $\mathrm{H}$ & 3 & 91 & liq \\
9 & $\mathrm{Br}$ & $4-\mathrm{COCH}_{3}$ & $\mathrm{H}$ & 2.5 & 93 & $110-112$ \\
10 & $\mathrm{Br}$ & $4-\mathrm{COCH}_{3}$ & $2-\mathrm{CH}_{3}$ & 3 & 83 & 94 \\
11 & $\mathrm{Br}$ & $4-\mathrm{CH}_{3}$ & $2-\mathrm{CH}_{3}$ & 3 & 90 & 273 \\
12 & $\mathrm{Br}$ & $4-\mathrm{NO}_{2}$ & $2-\mathrm{CH}_{3}$ & 2.5 & 92 & 102 \\
\hline
\end{tabular}

Reaction conditions: aryl halide $(1 \mathrm{mmol})$, boronic acid $(1.5 \mathrm{mmol})$, $\mathrm{K}_{2} \mathrm{CO}_{3}(2 \mathrm{mmol})$, Pd NPs in water $(2 \mathrm{~mol} \%, 10 \mathrm{~mL})$

${ }^{\text {a }}$ Isolated yield

b (Li et al. 2012)

functional groups in Fig. 2. A strong peak at $3,447 \mathrm{~cm}^{-1}$ corresponds to symmetrical stretching vibrations of $-\mathrm{OH}$ groups of hydroxyl molecules. The peaks at 2,924 and $2,847 \mathrm{~cm}^{-1}$ correspond to stretching vibrations of methyl and methoxy groups. A peak at 1,636 corresponds to bending vibrations of $-\mathrm{OH}$ groups. A strong peak at 1,049 corresponds to asymmetrical bending vibrations of $-\mathrm{CH}_{2}$ and $-\mathrm{CH}_{3}$ groups. These results confirm that the polyhydroxyl groups from WRAE have been adsorbed as a layer over the Pd NPs and in turn stabilize the synthesis of nanoparticles.

Figure 3 shows the AFM images of Pd NPs mediated by WRAE. For the AFM studies, the synthesized Pd NPs were dispersed in distilled water and were air dried on glass plates. As a result of air drying on the surface, a coffee ring phenomenon was observed for Pd NPs. As observed in Fig. 3, at the center of the drop, nanoparticles and aggregates were formed. It is well known that when liquids containing fine particles are evaporated on a flat surface, the particles accumulate on the outer surface and form typical structures (Chen and Evans 2009). Similar type of observations has been reported for Pd NPs mediated by Banana peel extract for SEM studies (Bankar et al. 2010).
TEM analysis was carried out to study the shape and size of the synthesized Pd NPs. Figure 4 shows the TEM images at different magnifications. The Pd NPs were found to be well dispersed and spherical in shape. Shape-controlled synthesis of nanoparticles is of interest to researchers due to its unique applications in catalysis. The display of shapecontrolled synthesis of Pd NPs mediated by WRAE makes the study unique for its industrial applications. Further, DLS measurements were carried out to obtain the size distribution of synthesized Pd NPs (Fig. 5). The average particle diameter of the synthesized Pd NPs was found to be $\sim 96.4 \mathrm{~nm}$ with polydispersity index of 0.243 .

Application in Suzuki coupling reaction

The Pd NPs synthesized using WRAE were employed as catalyst for Suzuki coupling reaction. The schematic reaction is represented in Fig. 6. The reaction was completed in the presence of $2 \mathrm{~mol} \% \mathrm{Pd}$ NPs at room temperature which resulted in good to excellent isolated yields of the products within short reaction times. A variety of substituted aryl bromides featuring either an electron-withdrawing or an electron-releasing group were then examined and results are summarized in Table 1 . The reactions proceeded smoothly with nearly quantitative yields. These results reveal the potential of Pd NPs synthesized by WRAE as efficient catalyst for industrial applications.

\section{Conclusion}

An attempt was made to study the potential of watermelon rind aqueous extract in synthesizing palladium nanoparticles. Conditions such as reactant ratio, $\mathrm{pH}$ and reaction time were standardized prior to characterization of synthesized Pd NPs. The synthesized Pd NPs were found to be shape controlled with spherical in shape with average particle size of $96 \mathrm{~nm}$. The FTIR peaks of Pd NPs revealed that polyhydroxyl groups of WRAE were involved in fabrication and stabilization of Pd NPs. Further, the synthesized Pd NPs were employed in Suzuki coupling reaction as catalyst and found to be efficient. These results suggest that watermelon rind, an agro waste, is capable of fabricating Pd to Pd NPs with catalytic applications. 
Acknowledgments Authors gratefully acknowledge the Management of VIT University, Vellore for encouraging and providing necessary facilities for carrying out this work.

Open Access This article is distributed under the terms of the Creative Commons Attribution License which permits any use, distribution, and reproduction in any medium, provided the original author(s) and the source are credited.

\section{References}

Andrew M, Zheng Y et al (2008) Structure of xylogalacturonan fragments from watermelon cell-wall pectin. Endopolygalacturonase can accommodate a xylosyl residue on the galacturonic acid just following the hydrolysis site. Carbohydr Res 343:1212-1221

Bankar A, Joshi B et al (2010) Banana peel extract mediated novel route for the synthesis of palladium nanoparticles. Mater Lett 64:1951-1953

Chen L, Evans JRG (2009) Arched structures created by colloidal droplets as they dry. Langmuir 25:11299-11301

Hebeish AA, El-Rafie MA et al (2010) Carboxymethyl cellulose for green synthesis and stabilization of silver nanoparticle. Carbohydr Polym 82:933-941

Jacob SJP, Finub JS et al (2012) Synthesis of silver nanoparticles using Piper longum leaf extracts and its cytotoxic activity against Hep-2 cell line. Colloids Surf B 91:212-214

Lakshmipathy R, Sarada NC (2013a) Adsorptive removal of basic cationic dyes from aqueous solution by chemically protonated watermelon (Citrullus lanatus) rind biomass. Des Water Treat. doi:10.1080/19443994.2013.812526
Lakshmipathy R, Sarada NC (2013b) Application of watermelon rind as sorbent for removal of Nickel and Cobalt from aqueous solution. Int J Miner Process 122:63-65

Lakshmipathy R, Vinod AV et al (2013) Watermelon rind as biosorbent for removal of $\mathrm{Cd}^{2+}$ from aqueous solution: FTIR, EDX, and Kinetic studies. J Indian Chem Soc 90:1147-1154

Li X, Yan XY et al (2012) Suzuki-Miyaura cross-couplings of arenediazonium tetrafluoroborate salts with arylboronic acids catalyzed by aluminum hydroxide-supported palladium nanoparticles. Org Biomol Chem 10(3):495-497

Narayanan KB, Sakthivel N (2011) Extracellular synthesis of silver nanoparticles using the leaf extract of Coleus amboinicus Lour. Mater Res Bull 46:1708-1713

Quek YS, Chok KN et al (2007) The physicochemical properties of spray-dried watermelon powders. Chem Eng Process 46: 386-392

Rimando MA, Perkins-Veazie MP (2005) Determination of citrulline in watermelon rind. J Chromatogr A 1078:196-200

Roopan SM, Bharathi A et al (2011) Acaricidal, insecticidal, and larvicidal efficacy of aqueous extract of Annona squamosa $\mathrm{L}$ peel as biomaterial for the reduction of palladium salts into nanoparticles. Colloids Surf B 92:209-212

Sathishkumar M, Sneha K et al (2009) Palladium nanocrystal synthesis using Curcuma longa tuber extract. Int J Mater Sci 4:11-17

Saxena A, Tripathi RM et al (2012) Green synthesis of silver nanoparticles using aqueous solution of Ficus benghalensis leaf extract and characterization of their antibacterial activity. Mater Lett 67:91-94

Yang X, Li Q et al (2010) Green synthesis of palladium nanoparticles using broth of Cinnamomum camphora leaf. J Nanopart Res 12:1589-1598 